\title{
Development of lyophilization cycle for direct thrombin Inhibitor and influence of excipients and process parameter during the cycle
}

\author{
*Sunil Kumar Panda ${ }^{1}$, Subas Chandra Dinda ${ }^{2}$ \\ ${ }^{1}$ School of Pharmaceutical Education and Research (SPER), Berhampur University, India \\ ${ }^{2}$ College of Health Sciences, Mekelle University, Mekelle, Ethiopia
}

\begin{abstract}
The objective of this study was to develop stable lyophilized product of Bivalirudin, a direct thrombin inhibitor with good reconstitution time, \% yield of good vials and cake quality. The \% loss of crystallinity was determined by DSC for any crys tallographic changes of the bulking agent after freeze drying. The glass transition temperature of $5 \% \mathrm{w} / \mathrm{v}$ of Bivalirudin, $3 \% \mathrm{w} / \mathrm{v}$ of mannitol and $0.03 \%$ of sodium acetate was approximately $-31^{\circ} \mathrm{C}$ and the collapse temperature was approximately $-28^{\circ} \mathrm{C}$. Tubular vials were found to withstand the thermal transition during freeze drying. Water content was inversely proportional to the primary drying set point. Reconstitution time was inversely proportional to annealing temperature and vacuum set point. The \% yield of good vials and cake quality was directly proportional to annealing time and primary drying set point. The \% loss of crystallinity by DSC was inde pendent of all factors and directly proportional to annealing time. Drying at $-10^{\circ} \mathrm{C}$ results in transition of $\beta$ form of mannitol, whereas drying at $-7.5^{\circ} \mathrm{C}$ and $-5^{\circ} \mathrm{C}$ results in $\alpha$ and $\delta$ form of mannitol respectively. On annealing at $-7^{\circ} \mathrm{C}$ for 54 minutes and drying at $-6.5^{\circ} \mathrm{C}$ at $215 \mathrm{mT}$ lyophilized product with less than $2 \%$ water content, reconstitution time less than 10 seconds, with high yield of more than $95 \%$ yield of good vials with best cake quality was obtained.
\end{abstract}

Key Words: Direct thrombin inhibitors, \% loss of crystallinity, reconstitution time, lyophilized, annealing temperature.

\section{INTRODUCTION}

The traditional management of cardiovascular disorders related to thrombosis is based on the use of heparin and oral anticoagulants. Novel direct thrombin inhibitors (DTIs), supersede heparin in multiple clinical trials. DTIs are indicated for the treatment and thromboprophylaxis of patients with heparin-induced thrombocytopenia (Ahmad, 2010). DTIs have numerous rewards over heparin, and present clinical benefit equivalent to that of a combination of heparin and antiplatelet agents such as clopidogrel bisulfate. The mechanism of DTIs is to inhibit platelet activation by activated serine protease. Heparins is known to have medical complications such as bleeding and the onset of a potentially catastrophic syndrome known as heparin-induced thrombocytopenia (HIT) associated with or without thrombosis. Because of their pharmacokinetic and biological advantages, direct thrombin inhibitors (DTIs), such as argatroban, bivalirudin and hirudin, have recently been developed as a heparin substitute for various clinical indication $(\mathrm{Ng}$ and Crowther, 2010). These cardiovascular agents are extensively used as alternative anticoagulant management of heparin-compromised patients, requiring therapeutic or interventional anticoagulation (Murphy and Marymont, 2007). The DTIs have revealed benefit due to their ability to inhibit both clot bound and circulating thrombin.

Among the antithrombotic therapies assessed so far, the synthetic peptide bivalirudin is distinctive in its ability to decrease both ischemic and bleeding complications associated with percutaneous coronary intervention (PCI). Bivalirudin is a small peptide consisting of 20 amino acid residues that binds thrombin in a direct, reversible, and bivalent fashion. Bivalirudin exhibits shorter half-life than

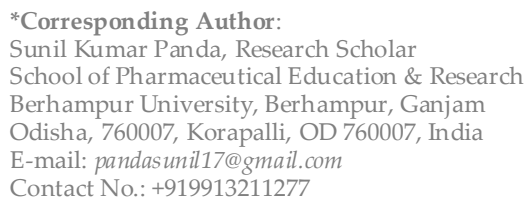

the indirect thrombin inhibitor, reduces the risk of bleeding during surgical procedure, reduces the risk of requiring blood transfusions during the treatment of the acute coronary syndrome.

In the Bivalirudin Angioplasty Trial (BAT), it was concluded by investigators that bivalirudin resulted in maintenance of safe and adequate anticoagulation. The Acute Catheterization and Urgent Intervention Triage strategy (ACUITY) trial demonstrated su perior net clinical outcomes with similar rates of ischemia and significantly less major bleeding with bivalirudin monotherapy compared to UFH/enoxaparin plus a GP IIb/IIIa inhibitor (Stone et al., 2006). Bivalirudin exhibits linear pharmacokinetics following intravenous administration and a halflife of approximately 25 minutes in patients with normal renal function, a volume of distribution of $13.0 \pm 0.7 \mathrm{~L}$, and a clearance rate of approximately $419 \pm 37 \mathrm{~mL} / \mathrm{min}$, or 3.4 $\mathrm{mL} / \mathrm{min} / \mathrm{kg}$ (Fox et al., 1993).

The formulation challenge for the formulation of $\mathrm{Bi}$ valirudin is related to its chemistry. It is a salt of Trifluoroacetic acid, hence gives an acidic $\mathrm{pH}$ in solution. Secondly, Bivalirudin is not stable at higher $\mathrm{pH}$. Bivalirudin is an amorphous powder with lowest solubility around its iso-electric point. Hence the influence of excipients, $\mathrm{pH}$, will influence the development of stable product. Since in aqueous solutions, $\mathrm{pH}$ is expected to influence Bivalirudin solubility, lyophilization is indispensable to keep it in stable form. The research article focuses on the development of stable product of Bivalirudin.

\section{MATERIALS AND METHODS}

\section{Materials}

Bivalirudin was obtained as a gift sample from Hospira, Chennai. Mannitol was obtained as gift sample from signet. All other reagents used were of analytical grade. 


\section{Methods \\ 1. Preparation of the solutions}

The preparation of the solutions in the measured vial was performed by weighing in each component in a flask on a reference balance (Sartorius, LA 120S), followed by subsequent filtration $(0.22 \mathrm{pm}$, Pall 8$)$ into the microbalance vial. The formulation of the surrounding vials was produced by volume and pipetted into the vials having regard to the fill depth of the solution. Formulation contains Mannitol USP as an excipient, Sodium Hydroxide NF and Trifluoroacetic acid as pH adjusting agents. All Excipients and active are freely soluble in water hence all ingredients were dissolved by simple mixing without any aid of heat. In order to maintain the $\mathrm{pH}$ within the limit throughout the shelf life, $\mathrm{pH}$ was adjusted to 5.5, the optimum value / the midpoint using Sodium Hydroxide NF and / or Trifluoroacetic acid.

2. Differential Scanning Calorimetry (Her and Nail, 1994) Differential scanning calorimeter (DSC) was conducted in scaled Al pan at 100 per minute using Shimadzu, D-50 DSC under $50 \mathrm{ml} / \mathrm{min}$ nitrogen purge. Samples (5-10 mg) were placed on one pan and the other aluminum pan was used a reference. It was heated from room temperature to $300^{\circ} \mathrm{C}$.

\section{Freeze-drying cycles}

Different freeze-drying cycles were tried and the freezedrying recipe was finalized. After termination of the drying cycle, vials were stoppered automatically and sealed.

\subsection{Determination of Collapse Temperature}

For the determination of glass transition and collapse temperature, the $3 \% \mathrm{w} / \mathrm{v}$ of mannitol, $5 \% \mathrm{w} / \mathrm{v}$ of bivalirudin and $0.03 \% \mathrm{w} / \mathrm{v}$ of anhydrous sodium acetate solution was freeze dried by using virtis 1000 Benchmark freeze dryer. The eutectic resistance at various temperatures was obtained by using the Encore software.

\subsection{Solution calorimetry}

Solution calorimeter measurements were measured at room temperature with a par solution calorimeter 1455 (Parr Instrument Company, USA) equipped with a par 1672 precision thermometer and a chart recorder. The thermo grams were recorded at a sensitivity of $10 \mathrm{mv}$ and $0.1^{\circ} \mathrm{C}$ on full scale and a chart speed of $2.5 \mathrm{~cm} / \mathrm{min}$. The measurements were performed under vigorous stirring (450 rpm). Heat calibration was conducted before measurement and the energy equivalence obtained was used for the corresponding heat calculation. For calibration the mass of TRIS (hydroxy methyl) amino methane was $500 \mathrm{mg}$ and the mass of $0.1 \mathrm{M} \mathrm{HC} 1$ was $100 \mathrm{gm}$. The freeze dried sample was accurately weighed just before measurements. Water was used a solvent $(100 \mathrm{~m} 1)$. The temperature changes during the reaction were detected and the reaction enthalpies were calculated. A negative value for the enthalpy indicated heat of evolution (exothermic Reaction) and a positive value indicated heat absorption (endothermic reaction). Heat capacity of mannitol was determined by DSC.

\subsection{Freeze thaw studies of glass vials}

$10 \mathrm{~m} 1$ and $50 \mathrm{ml}$, molded and tubular vials were obtained from Schott, Switzerland and Kaisha, India. 10 vials each from $0 \%, 2.5 \%, 5 \%, 8 \%$, and $10 \% \mathrm{w} / \mathrm{w}$ solution of mannitol were used. Into $10 \mathrm{~m} 1$ vial, $5 \mathrm{~m} 1$ solution was filled and to $50 \mathrm{~m} 1$ vial, $25 \mathrm{~m} 1$ solution was filled. Each set of vials were place in $-20^{\circ} \mathrm{C}$ and $50^{\circ} \mathrm{C}$, deep freezer and kept for 4 hours. After 4 hours, the vials from $-20^{\circ} \mathrm{C}$ deep freezer were shifted to $-50^{\circ} \mathrm{C}$ and vice versa. The total no. of vials breakage from each segment in each case was found out.

\subsection{Annealing time (Wang, 2000)}

The annealing time and temperature experiments utilized formulation of $3 \% \mathrm{w} / \mathrm{w}$ of mannitol and $5 \%$ bivalirudin and $0.03 \%$ sodium acetate. The $50 \mathrm{ml}$ vials were filled with $25 \mathrm{ml}$ of solution, partially stoppered and then the solutions were freeze dried. Samples were annealed on the freeze-dryer shelves maintained at the several temperatures. Then the samples were dried per the procedure just to get a freeze dried product. The ranges of each parameter were determined on the visual appearance and moisture content of the final product obtained after complete freeze drying cycles. Visual appearance indicates smooth surfaced cake and free flow of the cake.

3.5 Primary drying set point, secondary drying and Vacuum (Schneid and Henning, 2011)

The range of each parameters of primary drying i.e. Primary Drying Set Point and Vacuum Set Point was determined by performing several experiments. During the lyophilization cycle the freezing step was kept constant and the primary drying step was changed. As during the freeze drying cycle the samples were frozen up to $-40^{\circ} \mathrm{C}$. At this temperature the vapor pressure of the ice was just above $300 \mathrm{mT}$. The minimum vacuum attained during the cycle by the freeze drier was $100 \mathrm{mT}$. So the vacuum set point during the primary drying cycle was 100 to $300 \mathrm{mT}$.

\section{Water content}

The water content was determined by Karl Fischer method by using the Metrohm KF Titrator 790 Titrino with 703 Stirrer and TiNet 2,5 compliment software.

\section{Reconstitution time}

Reconstitution time was measured by injecting $25 \mathrm{~m} 1$ sterile water along the sidewall of the vial with gently shaking. A blank was prepared by adding $25 \mathrm{ml}$ water into a $50 \mathrm{~m} 1$ vial. Each sample was compared with blank after shaking. The reconstitution time was recorded at time point when the sample and blank was not distinguishable to visual clarity.

Table 1: Qualitative and quantitative composition of Bivalirudin.

\begin{tabular}{ccccc}
\hline S1. No. & Ingredient & $\begin{array}{c}\text { \% Quantity (as per } \mathbf{5 m L} \text { after } \\
\text { reconstitution) }\end{array}$ & Quantity (mg/vial) & Rationale \\
\hline 1 & Bivalirudin & $5.00 \%$ & 250 & Active ingredient \\
2 & Mannitol, USP & $3.00 \%$ & 150 & Bulking agent \\
3 & Sodium Hydroxide, NF & q.s. & q.s. to pH & pH adjusting agent \\
4 & Trifluoroacetic acid & q.s. & q.s. to pH & pH adjusting agent \\
\hline
\end{tabular}


Table 2: Lyophilization parameters.

\begin{tabular}{ccc}
\hline Hold & $25^{\circ} \mathrm{C}$ & $2 \mathrm{~min}$ \\
Rate & $-35^{\circ} \mathrm{C}$ & $24 \mathrm{~min}$ \\
Hold & $-35^{\circ} \mathrm{C}$ & $60 \mathrm{~min}$ \\
Rate & $0^{\circ} \mathrm{C}$ & $180 \mathrm{~min}$ \\
Rate & $40^{\circ} \mathrm{C}$ & $300 \mathrm{~min}$ \\
\hline
\end{tabular}

Table 3: Determination of collapsible and glass transition temperature.

\begin{tabular}{cccccc}
\hline $\begin{array}{c}\text { Temperature } \\
\left({ }^{\circ} \mathrm{C}\right)\end{array}$ & $\begin{array}{c}\text { Eutectic } \\
\text { resistance } \\
\text { (logMega } \\
\text { ohm) }\end{array}$ & $\begin{array}{c}\text { Temperature } \\
\left({ }^{\circ} \mathbf{C}\right)\end{array}$ & $\begin{array}{c}\text { Eutectic } \\
\text { resistance } \\
\text { (logMega } \\
\text { ohm) }\end{array}$ & $\begin{array}{c}\text { Temperature } \\
\left({ }^{\circ} \mathbf{C}\right)\end{array}$ & $\begin{array}{c}\text { Eutectic } \\
\text { resistance } \\
\text { (logMega } \\
\text { ohm) }\end{array}$ \\
\hline 27 & 1.5 & 4 & 2 & -19 & 3.3 \\
26 & 1.6 & 3 & 2 & -20 & 3.7 \\
25 & 1.6 & 2 & 2 & -21 & 4.2 \\
24 & 1.6 & 1 & 2.1 & -22 & 4.5 \\
23 & 1.6 & 0 & 2.1 & -23 & 4.6 \\
22 & 1.6 & 4 & 2.1 & -24 & 4.7 \\
21 & 1.6 & -2 & 2.2 & -25 & 4.7 \\
20 & 1.6 & -3 & 2.2 & -26 & 4.7 \\
19 & 1.7 & -4 & 2.2 & -27 & 4.7 \\
18 & 1.7 & -5 & 2.2 & -28 & 4.7 \\
17 & 1.7 & -6 & 2.2 & -29 & 4.8 \\
16 & 1.7 & -7 & 2.3 & -30 & 4.8 \\
15 & 1.7 & -8 & 2.3 & -31 & 6.6 \\
14 & 1.7 & -9 & 2.5 & -32 & 6.6 \\
13 & 1.8 & -10 & 2.5 & -33 & 6.6 \\
12 & 1.8 & -11 & 2.5 & -34 & 6.6 \\
11 & 1.8 & -12 & 2.6 & -35 & 6.6 \\
10 & 1.8 & -13 & 2.7 & -36 & 6.6 \\
9 & 1.8 & -14 & 2.7 & -37 & 6.8 \\
a & 1.8 & -15 & 2.7 & -38 & 6.8 \\
7 & 1.8 & -16 & 3.3 & -39 & 6.9 \\
6 & 1.8 & -17 & 3.3 & -40 & 7 \\
\hline
\end{tabular}

Table 4: Determination of physical parameter of mannitol.

\begin{tabular}{cc}
\hline Exp. No. & Forms of mannitol \\
\hline 1 & $\beta$ \\
2 & $\delta$ \\
3 & NA \\
4 & $\alpha$ \\
5 & $\delta$ \\
6 & $\delta$ \\
7 & $\alpha$ \\
8 & $\delta$ \\
\hline
\end{tabular}

\section{Cake quality}

Smooth surface uniform thickness, no shrinkage, no cake collapse, no melt back, no splashing and free flowing characterized the good freeze dried product. On this basis, the cake quality score was given to the entire freeze dried product.

\section{Yield of good vials}

$\%$ yield of good vials provide the efficiency and the robustness of the lyophilization

\section{RESULTS AND DISCUSSION}

Theoretical determination of duration of primary drying

Maximum no of $50 \mathrm{ml}$ vials can be loaded $=460$

Each vials contains water $=25 \mathrm{ml}$

Therefore total Amount of water was to be sublimed = 11.5 Liters
Condenser capacity of the freeze drier was 20 Liters / 24 hours

Thickness of the freeze dried products $=23 \mathrm{~mm}$

Therefore, total primary drying time $=11.5 / 20 \times 24 \times 23 /$ $10=\mathbf{3 0}$ hours

\section{Heat of solution of Mannitol}

Wt. of mannitol $=0.8 \mathrm{~m}$. Wt. of Water $=100 \mathrm{gm}$.

St of Solution $=0.5^{\circ} \mathrm{C}$

Specific heat of water $=4.2 \mathrm{~J} / \mathrm{gm}$.

Specific heat of mannitol $=14 \mathrm{~J} / \mathrm{gm}$.

Heat of solution $=$ (weight of water $x$ Specific heat of water + wt. of mannitol $x$ specific heat of mannitol)

Energy equivalent of calorimeter $=\{(100 \times 4.2+0.8 \times 14) \times$ $-0.5\}=23.2=-238.85 \mathrm{j} / \mathrm{gm}$

\section{Development}

Upon addition of Sodium Hydroxide immediately there was haziness which immediately turned to precipitate and upon continuous shaking the precipitate disappeared. After this $1 \mathrm{~N}$ Sodium Hydroxide solution was added slowly drop by drop until the solution $\mathrm{pH}$ was 14 . During this addition the solution was clear and no precipitate was observed this shows that there is no $\mathrm{pH}$ dependent solubility for Bivalirudin beyond $\mathrm{pH} 5$ and is completely soluble in this $\mathrm{pH}$ range. With reference to the characteristics observed in this study and in prototype 2 it was found that Bivalirudin is insoluble in the range of about $\mathrm{pH} 3.0$ to 4.5. Change in $\mathrm{pH}$ after addition of each excipient; Influence of addition of $\mathrm{pH}$ adjusting agent, addition of Bivalirudin before $\mathrm{pH}$ adjustment and addition of Bivalirudin after $\mathrm{pH}$ adjustment. The only excipient present in the formulation is mannitol USP. Mannitol is freely soluble in water and has no significant influence on solution $\mathrm{pH}$. Bivalirudin solubility is unaffected by addition of Mannitol USP, hence Mannitol is first solubilized in water at ambient tem perature.

\section{Addition of $p H$ adjusting agent}

The order of addition of excipients was kept common and two strategies were tried. Strategy 1 \& Strategy 2;Strategy 1; wherein Bivalirudin was added after addition of Sodium Hydroxide Strategy 2; wherein Bivalirudin was added before addition of Sodium Hydroxide.

Required quantity of Sodium Hydroxide in the form of solution was added slowly. At $\mathrm{pH} 3.2$ a precipitate was observed which was in soluble up to $\mathrm{pH}$ around 4.5. On further addition of Sodium Hydroxide the precipitate got solubilized in the mixture beyond $\mathrm{pH}$ 4.5. Based on this literature it was concluded that the precipitate found during the trial between $\mathrm{pH} 3.2$ and $\mathrm{pH} 4.5$ was Bivalirudin as it is the isoelectric point of the active material and is insoluble in that $\mathrm{pH}$ range.

\section{Glass transition and collapse temperature}

During primary drying, the product should be dried well above the collapse temperature to avoid the collapse of the cake. The glass transition temperature and collapse was obtained from the plot of eutectic resistance against temperature. Glass transition temperature was obtained by freezing the solution and recording the Eutectic resistance against temperature and the collapse temperature can be obtained by heating the frozen solution and recording the eutectic temperature against time. For the determination of Glass transition and collapse temperature, the $3 \% \mathrm{w} / \mathrm{v}$ of mannitol, $5 \% \mathrm{w} / \mathrm{v}$ of Bivalirudin and $0.03 \% \mathrm{w} / \mathrm{v}$ of anhydrous sodium acetate solution was freeze dried by using virtis 1000 Benchmark freeze dryer. 
Table 5: Annealing at temperature of $-20^{\circ} \mathrm{C}$ for 60 minutes.

\begin{tabular}{|c|c|c|c|c|c|c|}
\hline Hold & Rate & Rate & Hold & Rate & Hold & - \\
\hline \multicolumn{7}{|l|}{ Freezing } \\
\hline $25^{\circ} \mathrm{C}$ & $-35^{\circ} \mathrm{C}$ & $-20^{\circ} \mathrm{C}$ & $-20^{\circ} \mathrm{C}$ & $-35^{\circ} \mathrm{C}$ & $-35^{\circ} \mathrm{C}$ & - \\
\hline 2 Minutes & $240 \mathrm{~min}$ & $60 \mathrm{~min}$ & $60 \mathrm{~min}$ & $120 \mathrm{~min}$ & $60 \mathrm{~min}$ & . \\
\hline Hold & Rate & Hold & Rate & Hold & Rate & Hold \\
\hline P. Drying & Rate & Hold & Rate & Hold & Rate & Hold \\
\hline$-35^{\circ} \mathrm{C}$ & $-5^{\circ} \mathrm{C}$ & $-5^{\circ} \mathrm{C}$ & $0^{\circ} \mathrm{C}$ & $0^{\circ} \mathrm{C}$ & $20^{\circ} \mathrm{C}$ & $20^{\circ} \mathrm{C}$ \\
\hline 2 Minutes & $120 \mathrm{~min}$ & $1800 \mathrm{~min}$ & $120 \mathrm{~min}$ & $120 \mathrm{~min}$ & $120 \mathrm{~min}$ & $300 \mathrm{~min}$ \\
\hline $400 \mathrm{mT}$ & $350 \mathrm{Mt}$ & $300 \mathrm{mT}$ & $300 \mathrm{mT}$ & $300 \mathrm{mT}$ & $300 \mathrm{mT}$ & $300 \mathrm{mT}$ \\
\hline \multicolumn{7}{|l|}{ S. Drying } \\
\hline $25^{\circ} \mathrm{C}$ & & & & & & \\
\hline $\begin{array}{c}100 \text { Minutes } \\
100 \mathrm{mTa}\end{array}$ & & & & & & \\
\hline
\end{tabular}

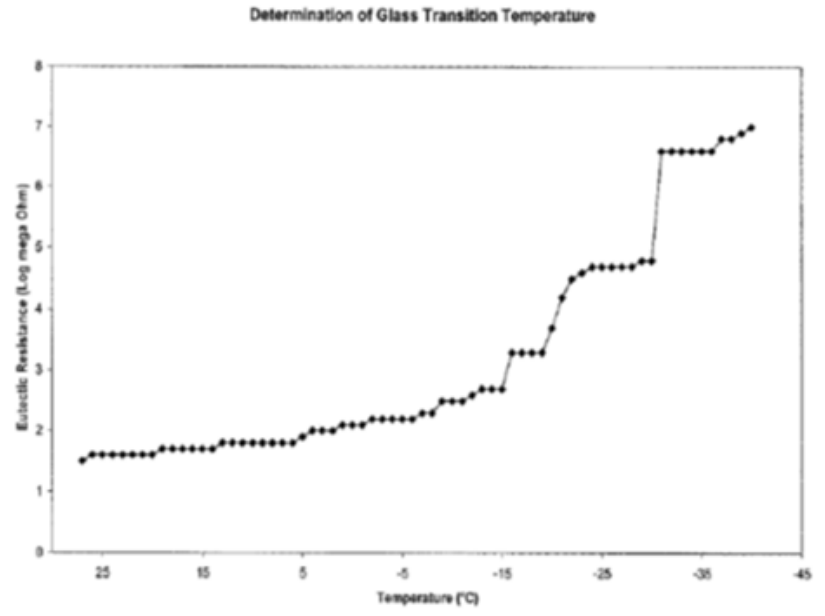

Figure 1: Eutectic resistance (Log mega ohm) during heating.

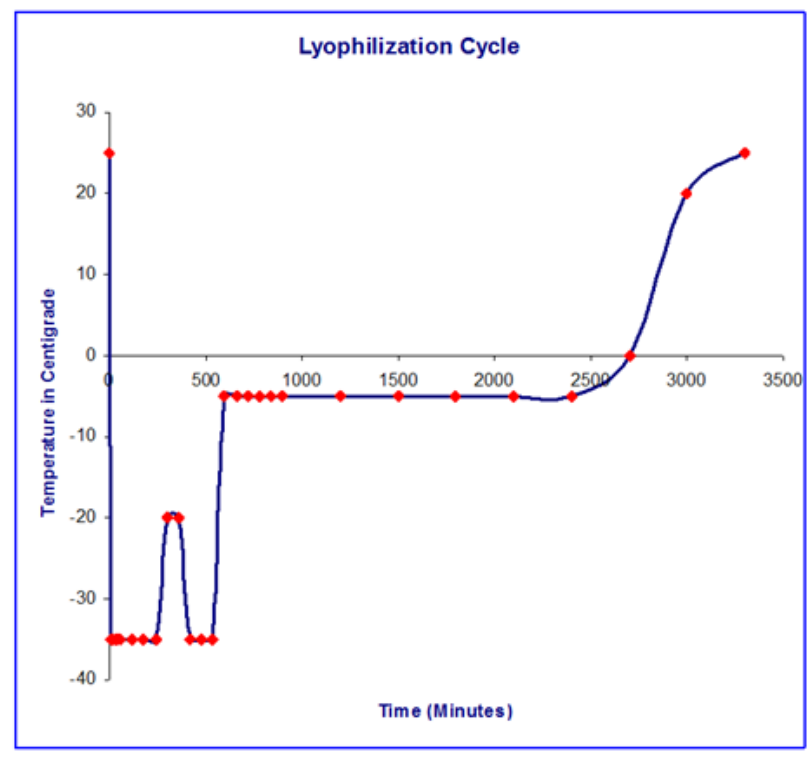

Figure 3: Annealing at temperature of $-20^{\circ} \mathrm{C}$ for 60 minutes (refer to table 5).

The eutectic resistance at various temperatures was obtained by using the Encore software. To obtain the glass transition temperature eutectic resistance was plotted against temperature. At about $-31^{\circ} \mathrm{C}$, the eutectic resistance increases rapidly and remains constant thereafter. At this temperature the complete solid mass of the solution is obtained. This temperature is the glass transition temperature. During the first inflection in

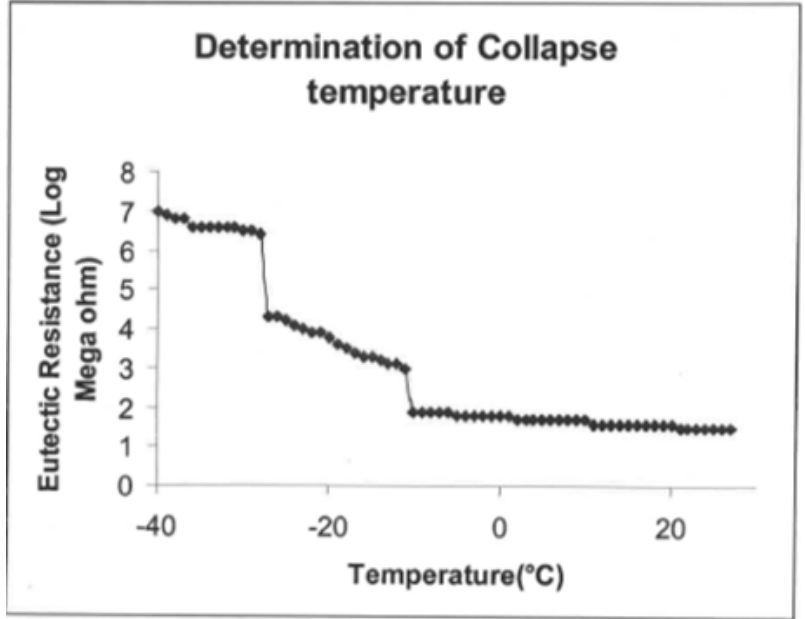

Figure 2: Eutectic resistance (Log mega ohm) during heating.

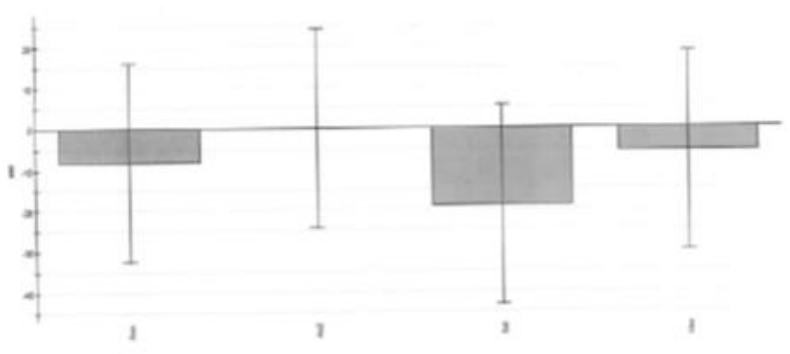

Figure 4: Scaled and centered coefficient for \% reconstitution time.

eutectic resistance was the Eutectic temperature and the second inflection in resistance is the glass transition temperature. Freezes suddenly to a solid mass the eutectic resistance increases was the eutectic temperature. At about decreases sharply was the collapse temperature. At about $-10^{\circ} \mathrm{C}$, the eutectic resistance decreases rapidly and remains constant thereafter. At this temperature the complete melting of the solution is obtained. This temperature is the melting temperature.

\section{Calorimetry}

The evaluation data for \% Loss of Crystallinity by solution calorimetry was given in the table-04. It can be concluded that the annealing temperature is inversely proportional to the $\%$ loss of crystallinity. In case of experiment, where the annealing time was 60 minutes, the \% loss of crystallinity by solution calorimetry was found to be 70.19 . The 


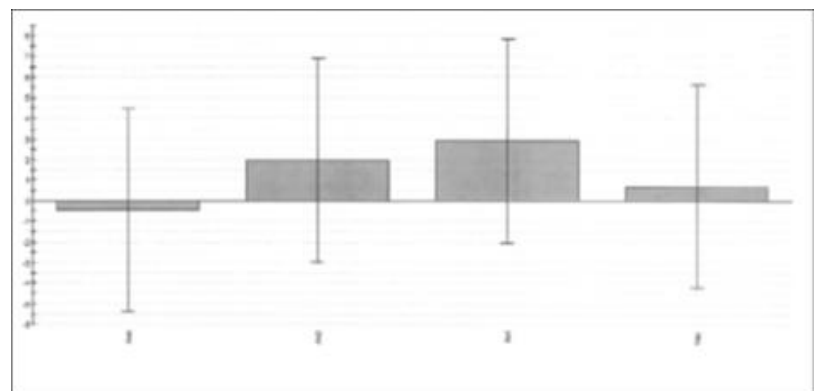

Figure 5: Scaled and centered coefficient for cake quality.

$\% \delta \mathrm{H}$ was found to be $48.68 \%$ while the $\%$ loss of crystallinity was found to be $51.32 \%$. From this it can be concluded that annealing time is directly proportional to the $\%$ loss of crystallinity. From the above results we may conclude that the Annealing temperature and annealing time factors are playing significant roles whereas the other two factors such as primary drying set point and Vacuum are not playing significant roles in \% loss of crystallinity by solution calorimetry. The scale and centered for coefficient of \% loss of crystallinity by solution calorimeters was obtained using PLS. The standard error Barr height of annealing temperature was deviating negatively from the center, the standard errors Barr height of annealing time was deviating positively from the center and the standard error Barr height of primary drying and set point and vacuum set point were not deviating significantly from center. \% loss of crystallinity by solution calorimetry was directly proportional to the annealing time and inversely proportional to the annealing temperature. The primary drying set point and vacuum set point had no significant role in loss in crystallinity. The lower the annealing temperature and higher the annealing time high would be the \% loss in crystallinity.

\section{Effects of freeze drying regimen on the physical parame-} ters of mannitol

On comparison with standards of XRD of Mannitol indicates the presence of a form of mannitol. The XRD did not corresponds to any known form $(\alpha, \beta, \delta)$ of Mannitol. On comparison of different forms of Mannitol with freeze drying parameters we may conclude that the primary drying set point is playing the major role. Primary drying at $-10^{\circ} \mathrm{C}$ results in $\beta$ form of Mannitol, and at $7.5^{\circ} \mathrm{C}$ results in $\alpha$ form of mannitol and at $-5^{\circ} \mathrm{C}$ results in $\delta$ form of Mannitol. During annealing partial melting of the cake occurred. The cake surface was not smooth. Few vials get collapsed on coming to the secondary drying. More vial breakage was seen (12\%). Moisture content was found to be $10.8 \%$. Moisture content taking into consideration the low moisture content was seen in the experiments where the annealing was done at $-5^{\circ} \mathrm{C}$, and $-10^{\circ} \mathrm{C}$ in comparisons to annealing at $0^{\circ} \mathrm{C}$ and $-20^{\circ} \mathrm{C}$. The Range of Annealing Temperature was kept in between -5 to $-15^{\circ} \mathrm{C}$ and annealing time from 30 to 60 minutes.

\section{Primary drying and Vacuum set point}

As during the freeze drying cycle the samples were frozen up to $-40^{\circ} \mathrm{C}$. At this temperature the vapor pressure of the ice was just above $300 \mathrm{mT}$. The minimum vacuum attained during the cycle by the freeze drier was $100 \mathrm{mT}$. So the vacuum set point during the primary drying cycle was 100 to $300 \mathrm{mT}$.

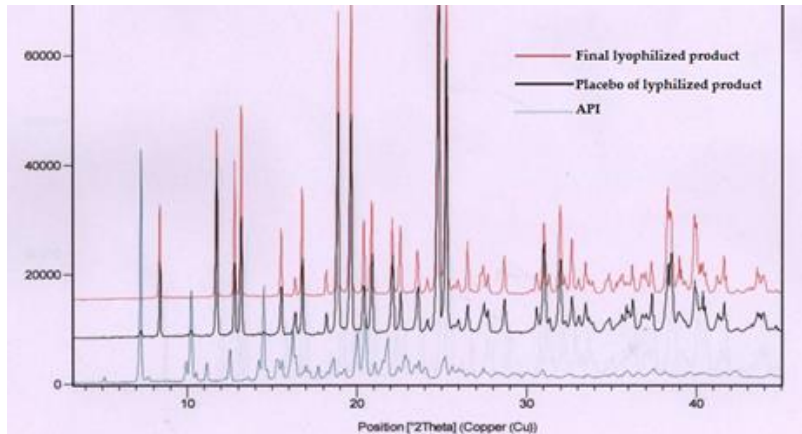

Figure 6: XRD of the lyophilized product.

\section{Effects of freeze drying parameters on moisture content} The scaled and centered coefficient for \% water of was obtained using PLS. Standard error height of primary drying set point was too much deviated negatively from center and standard error Barr height of annealing temperature. Annealing time and vacuum were not significantly deviated from the center .From this we may conclude that the \% water content in the freeze dried product was significantly dependent on the primary drying set point, whereas the annealing temperature, annealing time and vacuum were not playing significant role. Whereas the other parameters such as annealing temperature, annealing time and vacuum set point had no significant relationship with the moisture content. This can be correlated to the formation of drying channels created due to rapid heating at high vacuum. This probably made channel with continuous network of skeleton provides easy escape of water from the cake. If the primary Drying set point was more, the \% water would be less and vice Versa.

Effects of Freeze drying parameters on reconstitution time Annealing temperature and primary drying were inversely proportional to the reconstitution time. High the annealing temperature and vacuum were, low the reconstitution time and vice versa. The annealing temperature and primary drying set point was $-5^{\circ} \mathrm{C}$ and $5^{\circ} \mathrm{C}$, respectively, the reconstitution time was found to be 8 seconds.

\section{CONCLUSION}

The optimized cycle for moisture content is less than $2 \%$, reconstitution time is less than 10 seconds, \% yield is more than $95 \%$, with cake quality of score 10 and \% loss of crystallinity to $70 \%$, the cycle provided by the software was annealing temperature $-7^{\circ} \mathrm{C}$, annealing time at 54 minutes, primary drying set point $-6.5^{\circ} \mathrm{C}$, vacuum set point at $215 \mathrm{Mt}$. Following the cycle the moisture content was found to be $1.8 \%$, reconstitution time - 8 seconds, \% yield of good vials - $94 \%$ and cake quality scale between 9 to 10 .

\section{ACKNOWLEDGEMENT}

The authors are thankful to the authority of Berhampur University, India for the course of research studies.

\section{REFERENCES}

Fox I, Dawson A, Lyonds P et al. (1993). Anticoagulant activity of Hirulog, a direct Thrombin inhibitor, in humans. Thromb Haemost; 69: 157-63. PMid: 8456428

Her LM, Nail SL. (1994). Measurement of glass transition temperatures of freeze- concentrated solutes by differential scanning calorimetry. Pharm Res;11: 54-9. [DOI] PMid: 8140056 
Murphy GS, Marymont JH. (2007). Alternative anticoagulation management strategies for the patient with heparin-induced thrombocytopeni undergoing cardiac surgery. J Cardiothorac Vasc Anesth; 21: 113-26. [DOI] PMid: 17289495

$\mathrm{Ng} \mathrm{HJ}$, Crowther M. (2006). New anticoagulants and the management of their bleeding complications. Transfus Altern Transfus Med; 8(Suppl.1): 12-9. [DOI]

Ahmad S. (2010). Modulation of Serine Proteases-Mediated Platelet Activation by Novel Direct Thrombin Inhibitors Journal of Medical Sciences; 3(1): 44-53.
Schneid SC, Henning G. (2011). Rational approaches and transfer strategies for the scale up of freeze drying cycles. Chimica Oggi; 29: 43-6.

Stone GW, McLaurin BT, Cox DA. (2006). for the ACUITY Investigators. Bivalirudin for patients with acute coronary syndromes. N Engl J Med 355:2203-2216. [DOI] PMid:17124018

Wang W. (2000). Lyophilization and development of solid protein pharmaceuticals. Int J Pharm; 203:1- 60. [DOI] 